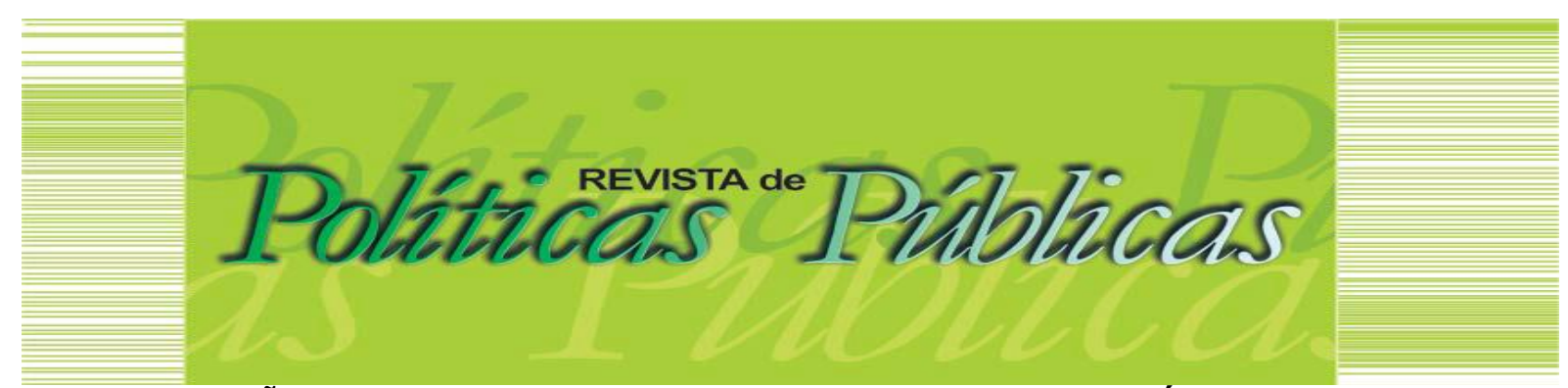

\title{
ACUMULAÇÃO DE CAPITAL E IDEOLOGIA NUMA ECONOMIA PERIFÉRICA: ensaio sobre o desenvolvimentismo brasileiro
}

\author{
Glauber Lopes Xavier ${ }^{1}$ \\ Roseli Martins Tristão Maciel2
}

\begin{abstract}
Resumo
0 presente texto tem por objetivo refletir sobre as abordagens do desenvolvimento, difundidas nos países periféricos, especificamente o caso do Brasil. Ressalta as características ideológicas do pensamento econômico latino americano cujos parâmetros são os processos de acumulação de capital nos países centrais. Fundamenta-se em Marx e no seu materialismo histórico dialético, cuja análise considera que a realidade social e sua dinâmica não existem no vazio e sim na sua historicidade e concretude, a fim de demonstrar a inconsistência e insuficiência das teorias econômicas para a compreensão do processo de desenvolvimento econômico na América Latina, e no Brasil.
\end{abstract}

Palavras-chave: Acumulação de capital. Desenvolvimento. Ideologia.

\section{ACCUMULATION OF CAPITAL AND IDEOLOGY IN A PERIPHERAL ECONOMY: essay on Brazilian developmentalism}

\begin{abstract}
The present text aims to reflect on the development approaches, spread in peripheral countries, specifically the case of Brazil. It highlights the ideological characteristics of Latin American economic thought whose parameters are the process of capital accumulation in central countries. It is based on Marx and his dialectical historical materialism, whose analysis considers that social reality and its dynamics do not exist in a vacuum but in their historicity and concreteness, in order to demonstrate the inconsistency and insufficiency of economic theories to understand the process of economic development in Latin America, and in Brazil.

Keywords: Capital accumulation. Development. Ideology.
\end{abstract}

Artigo recebido em: 03/02/2020 Aprovado em: 13/10/2020

DOI: http://dx.doi.org/10.18764/2178-2865.v24n2p532-545

\footnotetext{
${ }^{1}$ Economista. Doutor em Sociologia pela Universidade Federal de Goiás. Professor do curso de Ciências Econômicas e do Programa de Pós-Graduação Stricto Sensu em Territórios e Expressões Culturais no Cerrado da Universidade Estadual de Goiás. E-mail: glauberlx@gmail.com

2 Licenciada em História. Doutora em Políticas Públicas pela Universidade Federal do Rio de Janeiro (2014). Docente, efetiva, do curso de história da Universidade Estadual de Goiás e colaboradora do Mestrado em Territórios e Expressões Culturais do Cerrado.E-mail: roselitristaomacie@@gmail.com
} 


\section{INTRODUÇÃO}

Este trabalho tem como proposta discutir sobre o processo de acumulação de capital nos países denominados periféricos, especialmente o caso brasileiro, e apresentar o conteúdo ideológico intrínseco aos conceitos de desenvolvimento e desenvolvimentismo, difundidos pelas teses cepalinas ${ }^{1}$ e de vários economistas oriundos das mais diferentes correntes teóricas. Tem-se que 0 desenvolvimento e o desenvolvimentismo fundamentaram boa parte dos projetos de governos brasileiros no decorrer do século XX, fornecendo seu substrato ideológico e legitimando as iniciativas políticas.

Nesse sentido, apresenta uma breve revisão histórica e historiográfica a partir da análise das principais vertentes do pensamento econômico em relação aos conceitos de desenvolvimento e desenvolvimentismo. Trata, ainda, da acumulação de capital no Brasil desde seu período colonial a fim de demonstrar a gênese da inserção do país no sistema capitalista, considerando que através do pacto colonial a colônia atendia as finalidades de expansão e acumulação de capital, perseguidas pela Inglaterra, ainda que não fosse propriamente sua colônia.

$\mathrm{Na}$ sequência, discorre sobre as políticas desenvolvimentistas idealizadas e/ou implementadas pelos governos brasileiros a partir da década de 1930, momento em que Getúlio Vargas assume 0 poder e introduz, pela primeira vez no país, uma máquina governamental burocratizada e fundamentada na racionalidade técnica e científica com vistas a alcançar um nível de desenvolvimento econômico próximo ao dos países capitalistas. É desse projeto que emerge a ideologia do assim chamado desenvolvimentismo.

O trabalho está fundamentado na abordagem do materialismo histórico dialético, também denominada marxismo. Nesta perspectiva, a teoria e o método constituem recursos flexíveis e dependentes da realidade da qual buscam ser uma expressão, pois a realidade não é estática, é histórica, socialmente construída e determinada pelo curso dos eventos e das ideologias de uma dada época, qualquer que seja ela. Segundo Viana, (2007) o marxismo é uma teoria e método que se articulam para explicar o mundo material a partir de categorias de análise.

Ao postular a Lei Geral de Acumulação de Capital, capítulo XXIII do segundo volume, livro primeiro de $O$ capital, Marx (1968) pretendia explorar os nexos econômicos subjacentes aos processos sociais e históricos da acumulação. Assim, realizou interessante estudo sobre os distintos movimentos do capital e seus respectivos estágios. Para tanto, tomou a Inglaterra como lócus de suas investigações e, nela, encontrou substância para as formulações teóricas acerca da dinâmica de produção e reprodução do modo de produção capitalista. Marx apresentou a Lei do seguinte modo: 
entre o século XV e o século XVIII teria ocorrido a incorporação cada vez maior de trabalhadores nos processos produtivos, com 0 que se fez observar 0 crescimento dos salários e 0 crescimento proporcionalmente maior do capital variável em relação ao capital constante. A partir do século XVIII, no entanto, este movimento sofre substancial alteração.

Ao substituírem a força de trabalho, as máquinas levaram a um crescimento proporcionalmente superior do capital constante em relação ao capital variável, o que resultou, num terceiro momento (século XIX) no crescimento do quantitativo de trabalhadores sem trabalho, ou seja, na constituição de um exército industrial de reserva ou superpopulação relativa. Este processo é acompanhado, do ponto de vista do capital, por sua concentração e centralização, dando origem às grandes companhias empresariais dos últimos decênios do século XIX e, do ponto de vista do trabalho, pelo decréscimo dos salários e, portanto, pela piora das condições de vida do proletariado. 0 alcance dos mencionados estágios só se tornara possível porque previamente se dera uma acumulação de recursos, sem os quais não seria viável a garantia da reprodução simples do capital, num primeiro momento, e a reprodução ampliada num momento seguinte.

A este processo - a acumulação prévia- Marx denominou de acumulação primitiva do capital, tendo sido sua gênese marcada por processos de espoliação e pela definitiva separação entre os trabalhadores e os meios de produção. A história das economias periféricas latino-americanas remete a esse processo, cuja conexão com o centro dar-se-á graças à primazia do capital mercantil europeu e à exploração das colônias espanholas e portuguesa no limiar do século XVI. Com efeito, a periferia restará refém dos movimentos do capital ocorridos no centro, ao passo que fornecerá toda sorte de produtos naturais a fim de abastecer aqueles mercados. Certo é que esta relação será calcada na demanda cada vez crescente por alimentos e matérias-primas em face da expansão da força de trabalho empregada na manufatura europeia. Assim, nas colônias, impedidas do desenvolvimento de manufaturas próprias e, portanto, de condições para o surgimento do capitalismo industrial, vicejarão formas de emprego do trabalho caracterizadas por relações não capitalistas.

No caso do Brasil, ter-se-á como expediente a escravidão de populações negras provenientes do continente africano $e$, no tocante às colônias espanholas, a massiva exploração de povos autóctones por meio do instituto das encomiendas e da mita². Não resta dúvida de que a exploração das colônias concorrerá para a intensa acumulação de capital que grassava na Europa. É claro que o modelo mais exitoso de desenvolvimento das forças produtivas naquele contexto tratava-se do inglês, o qual encontrou, na América do norte, fonte de matérias-primas para o abastecimento de seu mercado, especialmente 0 algodão cultivado no sul escravista. Curioso notar que mesmo Adam Smith (1988), considerado o pai da doutrina liberal em matéria de economia, não deixou de reconhecer 
a relevância do mercado mundial para a expansão do capitalismo inglês. Para efeitos de estudo da peculiaridade histórica da América Latina e, principalmente, do caso brasileiro, não serão considerados os desdobramentos econômicos na colônia inglesa a que deu origem os Estados Unidos, embora ela possa ser, vez ou outra, reportada para intentos de comparação.

Especificamente sobre a acumulação de capital, o passado colonial impediu a constituição de um setor rural capitalizado e, pelas mesmas razões, bloqueou a possibilidade de formação de um contingente de força de trabalho assalariada. Reside aí, a nosso juízo, o fato de que na América Latina o capital tenha assumido mais a forma de dinheiro e de mercadoria do que propriamente a forma produtiva. Ou seja, nesses países, ao contrário daqueles cujo capitalismo já estava em franco processo de expansão, a acumulação não se integrava, pois que se limitava à circulação ao passo que apenas a produção permite que se possa auferir mais-valia e que se destine boa parte dela à nova produção. Estão nesse modelo de realização do capital as raízes da confusa relação trabalho produtivo e trabalho improdutivo na periferia.

Marx, no capítulo sobre a Teoria moderna da colonização (capítulo XXV), aponta para a peculiaridade histórica das colônias em face dos interesses metropolitanos, principalmente a problemática em torno da conversão de homens livres em trabalhadores assalariados somado à constituição de um mercado de terras. No caso brasileiro, essa problemática fica patente com a promulgação da Lei de Terras, de 1850, e as dificuldades encontradas por parte dos trabalhadores para 0 acesso à terra. Além disso, a relutância na manutenção da escravidão como relação de trabalho descortina um importante fundamento da nossa formação econômica (MARTINS, 2010). Ela permite explicar, ainda, a própria dinâmica geral de acumulação de capital nos casos de ex-colônias e cujos processos de desenvolvimento de seus capitalismos se deram tardiamente.

Sobre a primeira questão, o progresso das condições gerais de produção, especialmente no caso brasileiro, cujo processo de industrialização decorrido entre os anos de 1930 e 1980 foi o mais bem sucedido em comparação com os demais países latino-americanos, o aumento do trabalho improdutivo não se deu, em boa parte dos casos, associada às demandas da indústria. Pelo contrário, constituiu-se ao longo das décadas um contingente de trabalhadores ocupados em trabalhos precários, em atendimento às demandas da acelerada urbanização, bem como a persistência de uma agricultura de subsistência (OLIVEIRA, 2003). Reconhece-se, contudo, que tais fatores não forneceram impedimento ao alcance de estágios mais avançados da indústria nacional, a despeito do fato de que não se fez observar um crescimento orgânico da economia nos moldes da via clássica de desenvolvimento e tampouco houve completa similitude com a via prussiana. 
2 ACUMULAÇÃO DE CAPITAL NUMA ECONOMIA PERIFÉRICA: o caso brasileiro

Nossa particularidade reside na especificidade do nosso Estado, sua formação, um Estado parido das entranhas do colonialismo e seus nexos com o capital mercantil português, o que nos legou uma economia cujas raízes de sua dependência evocam a escravidão e a propriedade da terra como mediação das relações de trabalho e instrumento do poder, respectivamente. Isto significa compreender que terra, trabalho e dinheiro - as três mercadorias fictícias de que trata Polanyi (2012) ocuparam, aqui nos trópicos, outro papel e que a expansão do nosso capitalismo não implicou na conversão dos três elementos em mercadorias, ou seja, em mecanismos de obtenção do lucro via produção, mas de reprodução de prestígio social, de poder e de manutenção de determinado padrão de vida. A própria mentalidade da burguesia nacional pouco se assemelhava à mentalidade das burguesias europeias, especialmente a inglesa, para a qual não era desonroso acompanhar o trabalho fabril (LANDES, 1994).

É óbvio que esse passado conformou uma barreira ao nosso progresso material. Contudo, experiências históricas recentes mostraram que a despeito da dificuldade de superá-las, nenhuma delas se apresentou intransponivel. 0 problema é muito mais o contexto de sua superação, a conjunção de fatores internos e externos do que propriamente a decisão política a ser tomada. Para 0 caso brasileiro, o estado novo varguista ainda que tenha permitido a criação de instituições públicas fundamentais para o desenvolvimento econômico e que tenha impulsionado a industrialização via substituição de importações, não atacou o problema da terra e ainda manteve incólumes boa parte dos instrumentos pelos quais os cafeicultores mantinham assegurados seus lucros com as exportações de café.

Este problema, o da questão fundiária, permaneceu intocado durante 0 governo de Juscelino Kubitschek e durante os governos militares de Médici e Geisel, os que deram maiores incentivos ao processo de industrialização. Da mesma forma, a constituição de um mercado de capitais suficientemente forte a fim de ancorar os investimentos na formação/expansão da indústria se mostrou anódino diante da premente necessidade que se impunha. E, finalmente, os problemas ligados à esfera do trabalho (refiro-me à divisão regional e social do trabalho) não foram atacados, impedindo, portanto, a constituição de um mercado consumidor amplo e com rendimentos médios elevados. Como não empreendemos reformas estruturais (tributos, bancária, da terra, do trabalho) mantivemos uma economia que apesar de dirigida à industrialização, demonstrava-se claudicante diante de qualquer dificuldade externa. Assim ocorrera quando JK chegou a poder, tendo fornecido amplos benefícios ao 
capital estrangeiro, premido por um programa de desenvolvimento que demandava recursos numa magnitude sem par (LESSA, 1981; TAVARES; ASSIS, 1985).

O resultado foi uma forte crise política e econômica que nos conduziu ao autoritarismo. Se a ausência de democracia permitiu vigoroso crescimento do produto interno bruto, representou impedimento à sua repartição. Se logramos os estágios mais avançados da industrialização, isto significou um preço muito alto: desequilíbrio no balanço de pagamentos em virtude do endividamento e crescimento dos níveis inflacionários, sendo que os salários observaram perdas significativas agravando um quadro de profundas disparidades sociais e regionais. Foi o preço pago pela integração de um Departamento I (bens de produção) a um Departamento II (bens de consumo) sem a existência de um mercado de capitais nacional consolidado. Isto explica o porquê ficou nas mãos do Estado, via empresas públicas, a formação bruta de capital fixo, garantindo indústria de base e infraestrutura ao capital internacional porquanto este se realizava via investimento estrangeiro direto e fazia vultosas e crescentes remessas de lucros.

O desenvolvimento, para que pudesse ter sido logrado, requeria uma retroalimentação da própria indústria via novos investimentos, oriundos da própria acumulação, o que exigia mercado consumidor e não apenas investimento autônomo do governo. Disto, depreende-se que a Lei geral de acumulação comporta, na periferia, traços específicos. Contudo, a análise a que procedemos é fundamentalmente histórica, isto significa admitir que quando aqui se deu o processo de industrialização não se fez observar a ampliação dos salários em decorrência da crescente incorporação de novos trabalhadores. Assim, não houve formação de amplo mercado consumidor num primeiro momento. Além disso, a entrada das máquinas e o acelerado progresso técnico não se fez observar somente quando os salários estavam relativamente altos ao ponto de que os empresários preferissem substituir os braços pelas máquinas e, por fim, a concentração e centralização dos capitais não ocorreu nos quadros de uma consolidação do capitalismo nacional e a conquista de sua autossuficiência, isto é, conclamando a prática de políticas protecionistas na esteira daquilo que ocorreu na Alemanha no último quartel do século XIX.

Não se pretende aqui discorrer, em minúcias, sobre o nosso processo de industrialização, mas vale a pena apontar algumas particularidades: ao passo que os setores mais dinâmicos da indústria (indústria de transformação) ficaram nas mãos do capital estrangeiro, o capital nacional ocupou-se em boa parte da indústria tradicional (alimentos, bebidas, vestuário, dentre outras), dado que a primeira exige um volume muito alto de investimentos, principalmente em máquinas, ferramentas e equipamentos (MARINI, 2000). Os bens por ela produzidos (eletrodomésticos, equipamentos de toda sorte, automóveis dentre outros) destinavam-se a uma parcela reduzida da população enquanto a 
segunda, a indústria tradicional atendia principalmente a maior parcela dos consumidores, os quais auferiam baixos rendimentos e, portanto, destinavam a maior parte de seus ganhos para o consumo de alimentos, bebidas etc. Esta descrição sumária da indústria aqui instalada, a origem de seus capitais e o destino de suas mercadorias permitem compreender que a ausência de um amplo mercado interno, com salários relativamente altos, constituiu um dos principais impedimentos a um processo de industrialização com maior autonomia.

O cerne dessa problemática reside na formação do mercado de trabalho brasileiro, a produção e apropriação da riqueza nacional. Podemos compreendê-lo novamente com base na relação trabalho, terra e dinheiro, em como cada um desses elementos foi sendo convertido em mercadorias às avessas. O trabalho escravo deu lugar ao trabalho não assalariado no campo (relações sociais como parceria, meia, terça etc.), bem como a um trabalho precário nos centros urbanos (serviços e comércio ligados á cafeicultura principalmente); a terra, uma vez concentrada, permaneceu, em grande quantidade, improdutiva e finalmente o dinheiro, antes utilizado no comércio dos produtos agrícolas e dos escravos passou a ser meio de pagamento para trabalhadores mal remunerados em trabalhos precários, mormente urbanos ou foram drenados para a indústria que se fazia nascente por meio dos bancos. Até então (último quartel do século XIX) havia poucos bancos, sendo a maior parte das casas bancárias destinadas aos depósitos das divisas recebidas com as exportações de café.

O resultado desse processo é a formação de uma indústria nacional sem a devida demanda efetiva. A demanda em potencial era infinitamente superior àquela que se apresentava em face da ausência de rendimentos suficientemente altos. Outro resultado foi a precoce dependência do capital estrangeiro, posto que não havíamos constituído e consolidado mecanismos internos de financiamento e, por último, a ausência de sinergia entre o setor agrícola e o setor industrial, um grave problema cuja solução deveria passar pela reforma agrária. Tal constatação, específica ao setor rural, não admite, porém, a famigerada tese dos dois setores, tão defendida no passado recente.

Ou seja, ainda que não tenha ocorrido uma sinergia estrutural, o setor agrícola passou por profundas transformações, o que possibilitou sua modernização (dolorosa) e, em certa medida, sua convivência harmoniosa e colaborativa com a indústria (SILVA, 1981). É importante ressaltar que os anacronismos, assimetrias e distorções do processo de desenvolvimento do capitalismo nacional comporta relações com a própria dinâmica de desenvolvimento do capitalismo mundial. Sumarizando esse processo, podemos apontá-lo da seguinte forma. Quando colônia, foram impostas inúmeras dificuldades para o desenvolvimento da manufatura em território brasileiro. Ao longo do Brasil império, algum êxito foi alcançado, ainda assim o número de indústrias era pífio ao final do século XIX. 
A mudança do eixo de poder no Estado brasileiro a partir de 1930 trouxe à tona a necessidade de concretizar crescentes trasformações a nível político-social e impulsionar a industrialização iniciada nos grandes centros urbanos brasileiros. Isto se dá sobretudo depois dos anos 1920, período em que o governo se viu na contingência de admitir sua responsabilidade em relação à organização e ao controle político do país de forma centralizadora, promovendo alianças políticas com os mais diversos segmentos da sociedade civil.

As ações impetradas por Vargas são características da dominação legal que fundamenta o Estado racional moderno. Foi em seu governo que teve início a criação do tipo de estrutura de dominação que, na análise de Weber (1994), é o tipo ideal cuja forma mais pura de dominação legal se dá por meio da organização de um quadro administrativo do funcionalismo, ou seja, da burocracia, tal qual ocorrera na Europa a partir da implantação do sistema capitalista industrial. Ocorre que as ideias que balizaram o desenvolvimento do capitalismo industrial europeu foram anacrônica e distorcidamente incorporadas pela elite ilustrada brasileira.

O liberalismo vigente na Inglaterra, fundamental para a constituição das bases do capitalismo moderno (livre iniciativa, ampliação e especialização da divisão do trabalho, formação de sociedades empresariais), era defendido por alguns homens ilustrados e, quando muito, era anacronicamente evocado pelos parlamentares como forma de defesa de interesses das elites rurais escravocratas brasileiras. Daí que a questão da abolição da escravidão não tenha sido a bandeira de muitos homens que se intitulavam liberais. Seguramente, se a escravidão forneceu impedimento à formação de uma agricultura moderna ainda no século XIX, ela também impediu o progresso da indústria nacional, afinal de contas, era ela própria (o comércio de escravos) um negócio muito rentável. A aurora da indústria nacional se dá num contexto de turbulência externa (daí a necessidade crescente de substituição de importações) e ainda assim, não deixamos de abastecer os mercados externos por meio do nosso principal produto de exportação: 0 café 3 .

Importa, no entanto, ter em conta que a substituição de importações permitiu a remessa de capitais para economias mais avançadas mediante a importação de máquinas e equipamentos diversos lá produzidos e, não é demais afirmar - num contexto de aguda crise econômica mundial (pós crise de 1929). Em certa medida soubemos aproveitar o flanco aberto pela história; a nós foi imposto um desafio à lá Toynbee 4 e fornecemos uma resposta (a industrialização via substituição de importações ${ }^{5}$ ). O contexto seguinte, pós-segunda guerra mundial é um tanto distinto. Um novo ator despontava no cenário político e econômico mundial, a União das Repúblicas Socialistas Soviéticas (URSS) enquanto os Estados Unidos empreendiam o Plano Marshall a fim de recuperar as economias europeias e a japonesa de seus prejuízos com o conflito. Este contexto é importante porque 0 
desenvolvimento de economias tidas por atrasadas torna-se mote para uma série de iniciativas (FMI, Banco Mundial, Aliança para o Progresso, CEPAL) tendo em vista impedir que países subdesenvolvidos pudessem ser engolfados pela crescente e ameaçadora ideologia comunista propugnada pela URSS.

No tocante à acumulação de capital, o excesso de dólares permitirá a realização de empréstimos a vários países (caso do Brasil na segunda metade da década de 1950 com o governo de Juscelino Kubitschek) e a era de ouro americana espraiará por todo o mundo com o seu american way of life, disseminando os desejos de consumo daquela população e povoando o imaginário e as aspirações dos mais distintos povos. Como nosso processo de industrialização se realiza quando nas economias avançadas todo o processo já fora integrado e estas estão em plena disputa na esfera produtiva e financeira, não estaremos imunes aos efeitos provocados pelas políticas monetárias adotadas, principalmente o dólar, bem como as rápidas inovações no campo da tecnologia aplicada aos processos industriais.

Além disso, as próprias imposições no âmbito do comércio, seja a prática de políticas protecionistas seja a própria adoção de políticas cambiais seletivas. Nesse contexto, todos os esforços serão direcionados à promoção do desenvolvimento. É dele que emerge diversificada obra no campo das ciências sociais brasileiras, as quais elegerão como problemática a chamada "revolução burguesa" no Brasil.

\section{O DESENVOLVIMENTISMO COMO IDEOLOGIA DO CAPITALISMO PERIFÉRICO}

O conceito de desenvolvimentismo está revestido de conteúdo ideológico bem delineado. A ideologia cumpre importante papel para a manutenção e reprodução do sistema capitalista. No Brasil, o desenvolvimentismo será 0 viés ideológico ${ }^{6}$ através do qual é difundida a crença em um desenvolvimento autônomo, intrínseco ao capitalismo, capaz de promover o enriquecimento do país que, por sua vez, eliminará a desigualdade social e trará estabilidade e segurança nacional.

Recorrente nos debates políticos, bem como nos escritos acadêmicos, 0 desenvolvimentismo será a ideia-força por meio da qual o Estado atuará e os capitais serão mobilizados no contexto de uma economia periférica. Subjacente às principais interpretações, o dualismo conduzirá, enquanto matriz de pensamento, as elaborações teóricas e predições às políticas levadas a efeito pelo Estado. Tendo influenciado as teses cepalinas, destacadamente o pensamento de Celso Furtado, bem como as obras de Ignácio Rangel (2012) e Jacques Lambert (1973), o dualismo enfeixou uma ideologia, no campo da ciência econômica, em que o subdesenvolvimento seria uma 
etapa transitória para o alcance do desenvolvimento. Enquanto crítica a esta concepção, a obra Crítica à razão dualista, de Francisco de Oliveira e que veio a lume em 1971, tornou-se referência indispensável. Nas palavras de Oliveira (2003, p. 32-33):

O subdesenvolvimento pareceria a forma própria de ser das economias pré-industriais penetradas pelo capitalismo, em trânsito, portanto, para as formas mais avançadas e sedimentadas deste; todavia, uma tal postulação esquece que o subdesenvolvimento é precisamente uma produção da expansão do capitalismo.

Essa concepção coaduna-se àquela elaborada por André Gunder Frank acerca do "desenvolvimento do subdesenvolvimento", sob a qual erigiu-se a teoria marxista da dependência. Gunder Frank (1980) criticou o que chamou de círculo vicioso da "teoria desenvolvimentista" a que estariam presos os seus teóricos, seja pelo lado da oferta seja pelo lado da demanda. A obra de Furtado parece se filiar a esta corrente, sem, no entanto, recair na esterilidade do modelo neoclássico e tampouco cair na armadilha do etapismo proposto por W. Rostow (1961). "O subdesenvolvimento é, portanto, um processo histórico autônomo, e não uma etapa pela qual tenham, necessariamente, passado as economias que já alcançaram grau superior de desenvolvimento." (FURTADO, 2009, p. 161).

Ao mesmo tempo, parcela considerável de suas ideias acerca do subdesenvolvimento foi elaborada nos quadros da Comissão Econômica para a América Latina e o Caribe, da Organização das Nações Unidas, lastreando, portanto, sua orientação teórica e sua prática política. Este fato aponta especial atenção com a questão ideológica e institucional para a promoção do desenvolvimento, uma de suas pré-condições. Contrariando uma vez mais a noção de superação do atraso a partir do cumprimento de etapas, "[...] nos países atrasados, o efeito desses fatores básicos foi muito reforçado pelo uso de certos instrumentos institucionais e pela aceitação de ideologias específicas a favor da industrialização." (GERSCHENKRON, 2015, p. 73-74).

Ao conceber o subdesenvolvimento com base em noções mais amplas no âmbito da economia política, como a de imperialismo e a natureza do comércio mundial, Marini $(2000,2012)$, um dos principais nomes da teoria marxista da dependência, não compartilhava da ideologia do desenvolvimento ou o chamado desenvolvimentismo. Para Marini, a superexploração da força de trabalho tratava-se do fundamento da dependência. Somava-se a isto a importância crescente do capital estrangeiro e a transferência de lucros advindos da obtenção cada vez maior de parcelas de mais valor. Ressalte-se o fato de que a obra de Marini, ao contrário da teoria consagrada de origem cepalina, teve pouca ressonância no Brasil, tendo obtido maior projeção no Chile e no México. Não se tratava, pois, de ideias que se coadunavam aos propósitos da acumulação de capital. Pelo contrário, 
não apenas expunham o ciclo do capital nas economias dependentes como propunham uma saída revolucionária que seria protagonizada pelo proletariado latino-americano.

Com efeito, a ideologia do desenvolvimentismo tenta dar conta das realidades das economias dos países "subdesenvolvidos" ou "periféricos" tendo como ponto de partida as relações de produção do capitalismo, como um fato apriorístico, isto é, natural que sempre existiu. Assim sendo, desconsideram que 0 atraso econômico dessas sociedades advém justamente destas relações que foram construídas pelo capitalismo e que são necessárias para sua expansão e manutenção. Em outras palavras, não expressa o papel que o capitalismo desempenhou na história dessas economias periféricas, criando seus limites e barrando suas possibilidades concretas de desenvolvimento autônomo.

Os autores do desenvolvimentismo, portanto, analisando a partir de dados e não do processo histórico real, constroem ideologias e não teorias que dão conta de explicar historicamente 0 desenvolvimento e o subdesenvolvimento. São ideologias, uma vez que desconsideram o capitalismo como um sistema econômico historicamente construído e fundamentado nas relações de produção e transformação do trabalho em mercadoria que em seu processo de expansão chegam até as ditas economias periféricas. Sendo assim, para essas teorias, ou ideologias, a economia capitalista global é dividida entre desenvolvidas e subdesenvolvidas ao passo que o desenvolvimento econômico deve ocorrer "naturalmente" e por etapas.

As teorias desenvolvimentistas são importantes no sentido da manutenção, expansão e reprodução das relações sociais capitalistas, pois desvincula o conteúdo histórico da gênese e desenvolvimento deste sistema econômico. Como ideologia veicula e propaga os valores e interesses do sistema capitalista como sendo universais.

\section{CONSIDERAÇÕES FINAIS}

A acumulação de capital é condição para gênese, expansão e manutenção do sistema capitalista, isto é, trata-se de uma lei que Marx identificou e analisou ao explorar as relações econômicas implícitas em sua evolução social e histórica, tendo como lócus o caso da Inglaterra. Durante os séculos XVII e XVIII, a incorporação de uma grande massa de trabalhadores alienados de suas condições materiais de trabalho, e posteriormente, a introdução de máquinas, propiciou 0 crescimento proporcionalmente maior do capital variável em relação ao capital constante. Tais mudanças permitiram a constituição de um amplo exército industrial de reserva e, com isto, crescentes níveis de acumulação de capital. 
A manutenção do capitalismo só é possível a partir da reprodução de seu processo, desde sua gênese, marcada pelo divórcio entre os trabalhadores e os meios de produção. A acumulação econômica dos países latino-americanos articula-se a esta necessidade e processo, o que remete às expansões marítimas que resultaram na colonização e exploração do continente americano pelas metrópoles portuguesa e espanhola no século XVI. Assim, pode-se afirmar que a gênese da "não acumulação de capital" nas periferias ocupava um papel muito importante, qual seja o de proporcionar a extração e circulação de riquezas a partir da introdução do trabalho escravo, no caso do Brasil, e a exploração do trabalho autóctone no caso das colônias espanholas, drenando parte importante da riqueza para a Europa.

Entende-se que o modelo de desenvolvimento percorrido pelo capitalismo Europeu fornecerá um substrato ideológico às teorias produzidas na periferia e cuja roupagem será denominada de desenvolvimentismo. De Vargas, aos governos militares, até a inserção do Brasil no contexto neoliberal, as ações para a sua modernização partem das teorias da economia do desenvolvimento que tem em comum a ideia de que as economias capitalistas avançadas constituem o padrão, 0 modelo a ser referenciado.

Destarte, a compreensão das especificidades e obstáculos inerentes à América Latina e, no caso em particular do Brasil em seu processo de industrialização, é feita com base em uma perspectiva determinista. Grosso modo, tais abordagens desconsideram as particularidades históricas e sociais da realidade de cada país, sendo a concepção cepalina um importante exemplo. As teorias econômicas para os países periféricos nada mais são que ideologias que se fazem presentes na atualidade brasileira, constituem-se em concepções a-hitóricas, isto é, desvinculadas das realidades históricas que buscam compreender. É possivel afirmar que ainda existe um projeto nacional de desenvolvimento cujas raízes estão nos efeitos de retroalimentação ou dependência da trajetória, path dependence ${ }^{7}$,derivado dessas ideologias.

\section{REFERÊNCIAS}

CARDOSO, Ciro Flamarion; BRIGNOLI, Hector Peréz. Os Métodos da História. Rio de Janeiro: Graal, 1988.

CARDOSO, Ciro Flamarion; BRIGNOLI, Héctor Pérez. História econômica da América Latina. Rio de Janeiro: Edições Graal, 1983.

FURTADO, Celso. Desenvolvimento e subdesenvolvimento. Rio de Janeiro: Contraponto. Centro Internacional Celso Furtado, 2009. 
GERSCHENKRON, Alexander. 0 atraso econômico em perspectiva histórica e outros ensaios. Rio de Janeiro: Contraponto. Centro Internacional Celso Furtado, 2015.

GUNDER FRANK, André. Acumulação dependente e subdesenvolvimento: repensando a teoria da dependência. São Paulo: Editora Brasiliense, 1980.

LAMBERT, Jacques. Os dois brasis. São Paulo: Companhia Editora Nacional, 1973.

LANDES, David. Prometeu desacorrentado. Transformação tecnológica e desenvolvimento industrial na Europa ocidental, desde 170 até a nossa época. Rio de Janeiro: Nova Fronteira, 1994.

LESSA, Carlos. Quinze anos de política econômica. São Paulo: Editora Brasiliense, 1981.

MARINI, Ruy Mauro. O ciclo do capital na economia dependente. In: Ferreira, Carla; Osório, Jaime e Luce, Mathias (orgs.). Padrão de reprodução do capital: contribuições da teoria marxista da dependência. São Paulo: Boitempo, 2012.

MARINI, Ruy Mauro. Dialética da dependência: uma antologia da obra de Ruy Mauro Marini. Organização de Emir Sader. Petrópolis, RJ: Vozes; Buenos Aires: CLACSO, 2000.

MARTINS, José de Souza. 0 cativeiro da terra. São Paulo: Contexto, 2010.

MARX, Karl. 0 capital: crítica da economia política. Livro I, v. 2. Rio de Janeiro: Civilização Brasileira, 1968.

NETTO, Antônio Delfim. 0 problema do café no Brasil. São Paulo: Editora Unesp, 2009.

NORTH, Douglas C. Institutions, institutional change, and economic performance: Political E. of Institutions and Decisions. Cambridge: Cambridge University Press, 1990.

NORTH, Douglass C. Understanding the process of economic change. Princeton/Oxford: Princeton University Press, 2005.

OLIVEIRA, Francisco de. Crítica à razão dualista. São Paulo: Boitempo, 2003.

RANGEL, Ignácio. Dualidade básica da economia brasileira. Obras Reunidas. César Benjamin (org.). Rio de Janeiro: Contraponto. Centro Internacional Celso Furtado, 2012.

ROSTOW, W. W. Etapas do desenvolvimento econômico. Rio de Janeiro: Zahar Editores, 1961.

SILVA, José Graziano da. Modernização dolorosa: estrutura agrária, fronteira agrícola e trabalhadores rurais no Brasil. Rio de Janeiro: Zahar Editores, 1981.

SMITH, Adam. A riqueza das nações: investigação sobre sua natureza e suas causas. v. 1. São Paulo: Nova Cultural, 1988.

TAVARES, Maria da Conceição; ASSIS, J. Carlos de. 0 grande salto para o caos: a economia política e a política econômica do regime autoritário. Rio de Janeiro: Jorge Zahar Ed., 1985. 
TAVARES, Maria da Conceição. Da substituição de importações ao capitalismo financeiro: ensaios sobre economia brasileira. 6 ed. Rio de Janeiro: Zahar Editores, 1977.

VIANA, Nildo. A consciência da história: ensaios sobre materialismo histórico-dialético. Rio de Janeiro: Achiamé, 2007.

WEBER, Max. Economia e Sociedade. v.1. Brasília: UNB,1994.

\section{Notas}

1 Referentes às produções dos intelectuais ligados à Comissão Econômica para a América Latina e o Caribe.

2 Sobre esta questão, ver: CARDOSO, Ciro Flamarion; BRIGNOLI, Héctor Pérez. História econômica da América Latina.

${ }^{3}$ Sobre a problemática do café, ver: NETTO, Antonio Delfim. O problema do café no Brasil.

${ }^{4}$ Gerschenkron faz alusão à Toynbee ao tratar da história econômica da Europa no século XIX e a superação do atraso por parte de alguns países.

5 Sobre esse modelo de industrialização, seu auge e seu declínio, ver: Tavares (1977).

6 Trata-se da ideologia sujeita ao poder das classes e do Estado. Ver: CARDOSO, Ciro Flamarion; BRIGNOLI, Hector Peréz. Os Métodos da História. Rio de Janeiro: Graal, 1988, p. 18.

7 Ver North, (1990; 2005). 